\title{
Alpha-synuclein oligomer-selective antibodies reduce intracellular accumulation and mitochondrial impairment in alpha-synuclein exposed astrocytes
}

\author{
Gabriel Gustafsson', Veronica Lindström', Jinar Rostami , Eva Nordström², Lars Lannfelt ${ }^{1}$, Joakim Bergström', \\ Martin Ingelsson ${ }^{1}$ and Anna Erlandsson ${ }^{1 *}$
}

\begin{abstract}
Background: Due to its neurotoxic properties, oligomeric alpha-synuclein (a-syn) has been suggested as an attractive target for passive immunization against Parkinson's disease (PD). In mouse models of PD, antibody treatment has been shown to lower the levels of pathogenic a-syn species, including oligomers, although the mechanisms of action remain unknown. We have previously shown that astrocytes rapidly engulf a-syn oligomers that are intracellularly stored, rather than degraded, resulting in impaired mitochondria.

Methods: The aim of the present study was to investigate if the accumulation of a-syn in astrocytes can be affected by a-syn oligomer-selective antibodies. Co-cultures of astrocytes, neurons, and oligodendrocytes were derived from embryonic mouse cortex and exposed to a-syn oligomers or oligomers pre-incubated with oligomerselective antibodies.

Results: In the presence of antibodies, the astrocytes displayed an increased clearance of the exogenously added a-syn, and consequently, the a-syn accumulation in the culture was markedly reduced. Moreover, the addition of antibodies rescued the astrocytes from the oligomer-induced mitochondrial impairment.

Conclusions: Our results demonstrate that oligomer-selective antibodies can prevent a-syn accumulation and mitochondrial dysfunction in cultured astrocytes.
\end{abstract}

Keywords: a-synuclein oligomers, Astrocytes, Antibodies, Mitochondria, Lysosomal degradation, Parkinson's disease

\section{Background}

Cellular inclusions in the brain, referred to as Lewy bodies and Lewy neurites, are pathological hallmarks of Parkinson's disease (PD) [1]. The inclusions predominantly consist of $\alpha$-synuclein ( $\alpha$-syn) [2], a protein which aggregates into insoluble fibrils via the formation of soluble intermediates [3]. Such $\alpha$-syn oligomers are particularly harmful [4] and have for example been shown to disrupt

\footnotetext{
* Correspondence: anna.erlandsson@pubcare.uu.se

'Molecular Geriatrics, Department of Public Health and Caring Sciences,

Rudbeck Laboratory, Uppsala University, SE-751 85 Uppsala, Sweden

Full list of author information is available at the end of the article
}

cellular membranes $[5,6]$ and induce mitochondrial dysfunction $[7,8]$.

Targeting pathological $\alpha$-syn by either active or passive immunization has been shown to reduce $\alpha$-syn levels and ameliorate behavioral symptoms in transgenic mouse models of synucleinopathy [9-13]. Due to their toxic nature, immunization against soluble $\alpha$-syn oligomers is an especially attractive therapeutic target. Lewy body formation is believed to be protective rather than neurotoxic, and immunotherapy directed against fibrillar $\alpha$-syn is therefore less likely to be effective. We have previously shown that treatment with antibodies directed against oligomeric $\alpha$-syn lowers the CNS levels of 
oligomers in a transgenic $\alpha$-syn-expressing mouse model [9]. However, the cellular mechanisms by which the antibodies act and which cell types are targeted remain unknown.

Although $\alpha$-syn deposits are primarily found in neurons in the PD brain, they also appear frequently in astrocytes [14-19]. Being the most numerous glial cell type in the CNS, astrocytes have great impact on the brain environment and may constitute a very potent treatment target. Astrocytes play an important role in maintaining brain homeostasis [20], and their functions include metabolic support of neurons, modification of synapse signaling, recycling of neurotransmitters, blood brain barrier regulation, and glymphatic clearance [20-22]. In addition, astrocytes respond to neurodegenerative disorders, including PD, through astrogliosis, a process in which they convert to a reactive inflammatory state [23, 24]. Yet, the role of astrocytes in the development and progression of $\alpha$-syn pathology has been infrequently studied. In a recent study, we investigated uptake, degradation, and toxic effects of soluble oligomeric $\alpha$-syn in a co-culture system consisting of predominant astrocytes and, to a lesser extent, neurons and oligodendrocytes [25]. In contrast to neurons, the astrocytes were found to rapidly ingest large amounts of $\alpha$ syn. Due to incomplete digestion, intracellular $\alpha$-syn deposits remained in the astrocytes, which resulted in a mitochondrial impairment [25].

The aim of the present study was to investigate whether $\alpha$-syn oligomer-selective antibodies can affect astrocytic accumulation of $\alpha$-syn oligomers in vitro. The oligomer-selective antibodies used in this study have approximately 500 -times higher affinity for oligomers compared to monomeric protein [26]. Interestingly, we found that oligomer-selective antibodies effectively prevented astrocytic accumulation of exogenously added $\alpha$ syn oligomers. Moreover, the antibodies rescued the astrocytes from mitochondrial fragmentation. Our results suggest that immunotherapeutic approaches involving antibodies selective for soluble $\alpha$-syn oligomers could improve astrocyte functioning, including their neuroprotective effects in alpha-synucleinopathies.

\section{Methods}

\section{Animals}

All animal experiments were approved by the Uppsala County Animal Ethics Board, following the rules and regulations of the Swedish Animal Welfare Agency and were in compliance with the European Communities Council Directive (2010/63/EU). The animals were housed at the Uppsala University Hospital in a 12:12 dark:light cycle. The mice were kept in an enriched environment and given water and food ad libitum. Embryonic C57BL/6 mice were used for the cell culture experiments.

\section{Neural cell culture}

Cortices from 14-day-old mouse embryos (E14) were dissected, and neurospheres were prepared and differentiated as previously described [27]. The cells were expanded in DMEM/F12-GlutaMAX supplemented with $1 \times \mathrm{B} 27,50 \mathrm{U} / \mathrm{ml}$ penicillin, $50 \mathrm{mg} / \mathrm{ml}$ streptomycin and $8 \mathrm{mM}$ Hepes buffer; $10 \mathrm{ng} / \mathrm{ml}$ bFGF (all from Invitrogen); and $20 \mathrm{mg} / \mathrm{ml}$ EGF (VWR). The neurospheres were passaged every second or third day by mechanical dissociation. Prior to experiments, the cells were plated as a monolayer, at a concentration of $1.5 \times 10^{4}$ cells $/ \mathrm{ml}$ on cell culture dishes or coverslips coated with poly-Lornithine $(0.0025 \%$, Sigma-Aldrich) and laminin $(1 \mu \mathrm{g} /$ $\mathrm{ml}$, Invitrogen). After $24 \mathrm{~h}$, the media was replaced with mitogen-free media (DMEM/F12-GlutaMAX supplemented with $1 \times \mathrm{B} 27,50 \mathrm{U} / \mathrm{ml}$ penicillin, $50 \mathrm{mg} / \mathrm{ml}$ streptomycin, and $8 \mathrm{mM}$ Hepes buffer (all from Invitrogen)) to initiate neural stem cell differentiation to a mixed population of neurons, astrocytes, and oligodendrocytes, but not microglia. This is a well-characterized cell culture system, based on the lineage-restricted differentiation of embryonic, cortical stem cells [28-30]. By using immunocytochemistry, we have previously confirmed that the culture (after 1 week of differentiation) consists of a mixed population of neurons (20\%), astrocytes $(75 \%)$, and oligodendrocytes (5\%), but importantly no microglia [25]. Neurospheres from passages $1-3$ were used for the experiments.

\section{Generation and labeling of HNE-induced $a$-syn oligomers}

Recombinant $\alpha$-syn was produced as previously described [31]. Monomeric $\alpha$-syn $(140 \mu \mathrm{M})$ was incubated with 4hydroxy-2-nonenal (HNE) (Cayman Chemicals) in a HNE: $\alpha$-syn molar ratio of $30: 1$ at $37{ }^{\circ} \mathrm{C}$ for $72 \mathrm{~h}$. To control the ratio of oligomerization, samples were analyzed with SEC-HPLC, previously described in [25]. The characteristics of the oligomers have been thoroughly described [31]. In short, the size of the oligomers is about $2000 \mathrm{kDa}$ and their width is $100-200 \mathrm{~nm}$. Moreover, they are stable and $\beta$-sheet rich but do not form fibrils. The $\alpha$-syn oligomers were labeled with $\mathrm{Cy} 3$ using Amersham Cy3 Antibody Labeling Kit (GE Healthcare (cat. \# PA33000)). Unbound excess $\mathrm{Cy} 3$ was removed by filtration in a Zeba spin desalting column (Thermo Scientific).

\section{Alpha-synuclein and antibody exposure}

Alpha-synuclein oligomers were pre-incubated with the $\alpha$-syn oligomer-selective antibodies, mAb47 (IgG1) [9], mAb49G (IgG1) [32], or mAb38E2 (IgG2b), generated by the research group [26] at a 1:1 ratio $(0.05 \mu \mathrm{M})$ in regular growth media at $37{ }^{\circ} \mathrm{C}$ for $1 \mathrm{~h}$. The co-cultures were then exposed to $0.05 \mu \mathrm{M}$ oligomers or to oligomers pre-incubated with antibodies. To analyze the effect of mAb47 on $\alpha$-syn accumulation further, mAb47 was 
added after the 24-h $\alpha$-syn oligomer exposure. The cultures were thoroughly washed in cell culture media prior to the antibody addition and cultured with the antibody for $24 \mathrm{~h}$. In another control experiment, the co-cultures were incubated with mAb47 for $24 \mathrm{~h}$ and then extensively washed in cell culture media, prior to 24-h $A \beta_{42}$ protofibril exposure. As negative control antibodies, the irrelevant antibody mAb-Ly128 (IgG ${ }_{1}$, Mabtech), recognizing flagellin in bacteria, were used. For visualization of mitochondria, the cultures were transfected with Cell light Mitochondria-GFP (BacMam 2.0, Life Technologies) during the oligomer exposure. After $24 \mathrm{~h}$ of oligomer exposure, conditioned media was collected and the cells were washed in fresh media and fixed or lysed for further analyses. Cells were also recorded using a timelapse microscope (Nikon Biostation IM Cell Recorder), during exposure to $\alpha$-syn oligomers $(0.05 \mu \mathrm{M})$ or to oligomers pre-incubated with mAb47 $(0.05 \mu \mathrm{M}, 1: 1$ ratio). Images (40X) were captured every $10 \mathrm{~min}$ for $24 \mathrm{~h}$.

\section{Lysosomal inhibition}

In order to investigate the influence of the endosomal/ lysosomal pathway on the antibody-mediated $\alpha$-syn reduction in astrocytes, cells were pre-incubated with two different lysosomal inhibitors. Co-cultures were incubated with the lysosomal inhibitors bafilomycin (Baf; Calbiochem, Millipore 196000, $0.5 \mu \mathrm{M}$ ) or chloroquine (Chq; Sigma, C6628, $10 \mu \mathrm{M}$ ) for 30 min prior to addition of $\alpha$-syn oligomers or oligomers pre-incubated with mAb47. The inhibitors remained in the media during the 24-h exposure. Following fixation, the accumulation of $\alpha$-syn oligomers was assessed by immunofluorescence. The inhibitors did not have any apparent toxic effects in the concentration and exposure times used.

\section{Immunocytochemistry}

Cells were cultured on coverslips and fixed with 4\% PFA for $15 \mathrm{~min}$ at room temperature (RT). The cells were then permeabilized and blocked for $30 \mathrm{~min}$ at RT in $0.1 \%$ Triton X-100 $+5 \%$ normal goat serum (NGS) in PBS and incubated for $1 \mathrm{~h}$ at RT with primary antibodies diluted in $0.1 \%$ Triton X-100 $+0.5 \%$ NGS in PBS. The primary antibodies used were polyclonal rabbit antiGFAP (DAKO, 1:400) or monoclonal mouse anti-GFAP (Sigma, 1:400), specific for astrocytes; mAb38F, (1:100), selective for $\alpha$-syn oligomers [26]; and rabbit polyclonal anti-Lamp-1 (Abcam, 1:200), a lysosomal marker. Following washing $3 \times$ in PBS, the samples were incubated with secondary antibodies: goat anti-rabbit IgG $(\mathrm{H}+\mathrm{L})$, Alexa Fluor 488 conjugate antibody; goat anti-mouse IgG $(\mathrm{H}+\mathrm{L})$, Alexa Fluor 488 conjugate antibody; or goat anti-mouse IgG $(\mathrm{H}+\mathrm{L})$, Alexa Fluor 647 conjugate antibody (Life Technologies, 1:200) in $0.1 \%$ Triton X-100 + $0.5 \%$ NGS in PBS at RT for $1 \mathrm{~h}$. Then, the coverslips were washed and mounted using Vectashield Hard Set with DAPI (Vector Laboratories). Internalization of the $\alpha$-syn oligomer-selective antibodies was detected by staining of permeabilized samples for mouse IgG with a secondary goat anti-mouse 488 antibody (Alexa, Life Technologies, 1:200).

\section{ELISA}

To assess Ab: $\alpha$-syn oligomer complex formation, an $\alpha$ syn oligomer-selective ELISA was used as previously described [26]. A reduced ELISA signal was interpreted as interference due to $\mathrm{mAb} 47$ binding to oligomers and obstruction of $\mathrm{mAb} 38 \mathrm{~F}$ binding, in either the capture or detection steps. In short, oligomers were incubated with or without mAb47 $(0.05 \mu \mathrm{M}, 1: 1$ ratio) $1 \mathrm{~h}$ in regular media for $37{ }^{\circ} \mathrm{C}$. High-binding 96-well polystyrene plates (Costar 3590) were coated with the oligomer-selective antibody mAb38F (100 ng/well) diluted in PBS overnight $\left(4{ }^{\circ} \mathrm{C}\right)$. The plate was blocked with $1 \%$ bovine serum albumin for $2 \mathrm{~h}$ before adding the $\alpha$-syn oligomer standards $(0-250 \mathrm{pM})$, or cell lysate samples were added to the wells and incubated for $2 \mathrm{~h}$, followed by incubation with biotinylated mAb38F (100 ng/well) for $1 \mathrm{~h}$ and Streptavidin-HRP (1:5000, Mabtech) for $45 \mathrm{~min}$. Finally, TMB (Neogen) was used as a substrate and the plates were analyzed at $450 \mathrm{~nm}$ (Infinite M1000, Tecan). In addition, a sandwich ELISA was used to quantify the total $\alpha$-syn levels in the cultures. Conditioned media from three different experiments $(n=3)$ was collected after $24 \mathrm{~h}$ of exposure to $\alpha$-syn oligomers or oligomers pre-incubated with antibody. The ELISA was performed as described above, but using Syn-1 $(1 \mu \mathrm{g} / \mathrm{ml}, 610,787$, BD Biosciences) as capture antibody and FL-140 (1 $\mu \mathrm{g} /$ $\mathrm{ml}$, sc-10717, Santa Cruz Biotechnology) for detection. The samples were diluted 1:200 prior to loading on ELISA wells.

\section{Immunoprecipitation and Western blot}

Conditioned media were collected after $24 \mathrm{~h}$ exposure to $\mathrm{mAb} 47+\alpha$-syn oligomer and stored at $-70{ }^{\circ} \mathrm{C}$. The media were thawed on ice and incubated with 3-mg magnetic beads (Dynabeads, Novex, Life Technologies) with rotation for $2 \mathrm{~h}$ at RT. The beads were washed three times, and the protein was eluted for $10 \mathrm{~min}$ at $70{ }^{\circ} \mathrm{C}$, in the presence of LDS sample buffer and sample reducing agent (Bolt, Life technologies). Gel electrophoresis was carried out with the eluate on a $4-12 \%$ Bis-Tris Plus gel (Bolt, Life Technologies) for $28 \mathrm{~min}$ at $200 \mathrm{~V}$ in SDS MES running buffer (Bolt, Life Technologies). Chameleon kit pre-stained protein ladder (Li-Cor) was used as a standard. Transfer onto a PVDF membrane was performed for $1 \mathrm{~h}$ at $20 \mathrm{~V}$ (Novex, Life Technologies). The membrane was blocked with Odyssey TBS blocking buffer (Li-Cor) for $1 \mathrm{~h}$ at RT. After brief 
washing in TBS-T, the membrane was incubated with the mouse-anti- $\alpha$-syn antibody mAb211 (Santa Cruz, sc$12,767,1: 500)$ in $0.5 \mathrm{X}$ Odyssey blocking buffer in TBS-T at $4{ }^{\circ} \mathrm{C}$ overnight. Washing $(3 \times 10 \mathrm{~min}$ in TBS-T) was followed by incubation with secondary antibody DyLight
680 goat anti-mouse (Li-Cor, 1:10,000) in 0.5X Odyssey blocking buffer in TBS-T for $1 \mathrm{~h}$ (RT). Washing $3 \times$ $10 \mathrm{~min}$ in TBS-T was followed by imaging in an Odyssey SA infrared imaging system (Li-Cor). Regular media was used as a negative control, and media containing
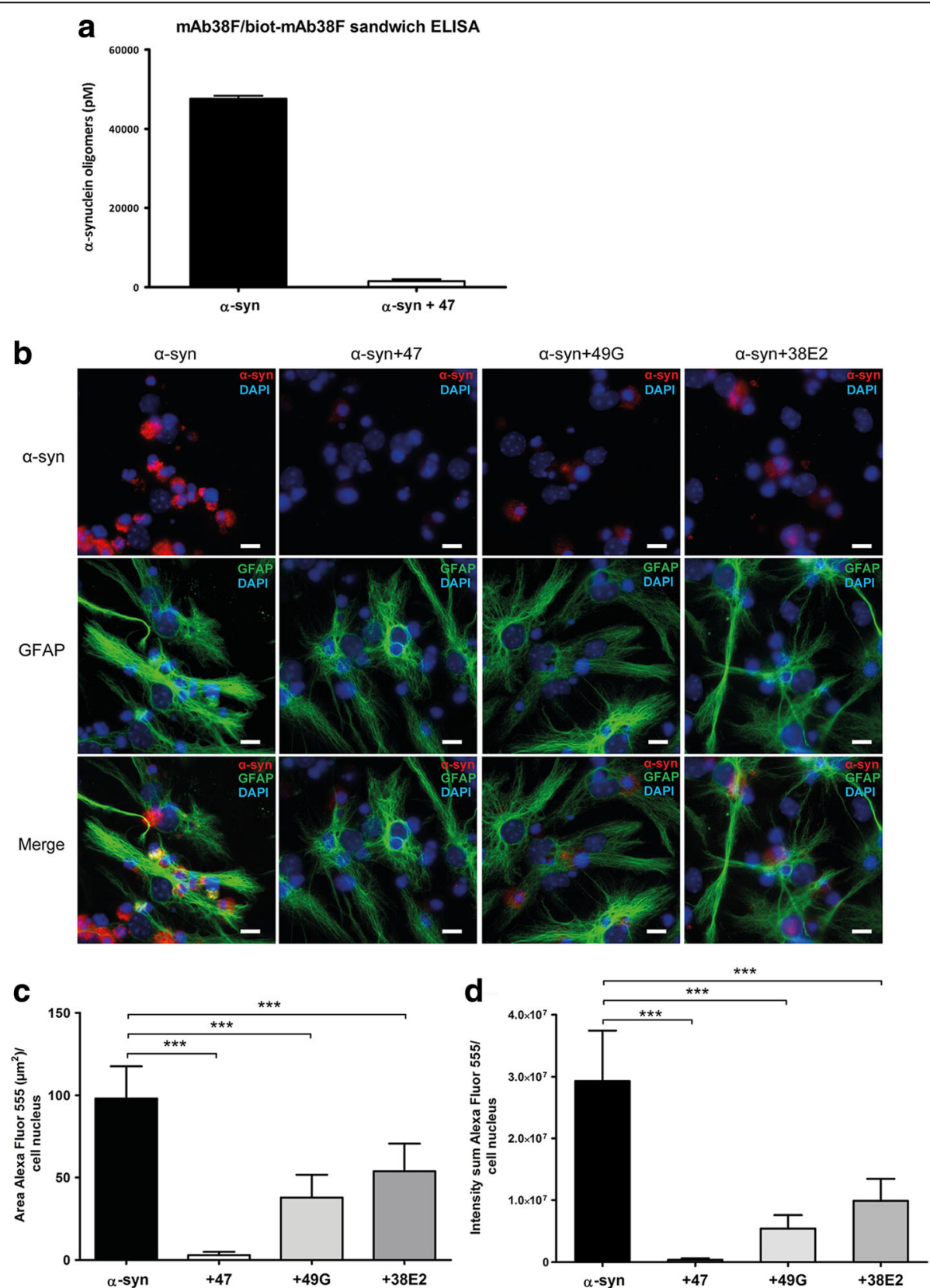

Fig. 1 Oligomer-selective antibodies reduce a-syn oligomer accumulation in astrocytes. a a-syn oligomers incubated with mAb47 (0.05 $\mu \mathrm{M}, 1: 1$ ratio) $1 \mathrm{~h}$ at $37^{\circ} \mathrm{C}$ were analyzed with mab38F/biot-mab38F sandwich ELISA. The addition of mAb47 resulted in a strong reduction of the a-syn oligomer signal, implying steric hindrance by mAb47 due to high Ab:a-syn oligomer complex formation. b Cells were exposed to fluorescent a-syn oligomers or to oligomers pre-incubated with the a-syn oligomer-selective antibodies: mAb47, mAb49G, or mAb38E2, for $24 \mathrm{~h}$. The a-syn accumulation was strongly reduced when oligomers had been pre-incubated with antibodies. The mAb47 had the most pronounced reducing effect on a-syn oligomer accumulation. Measurements of the intracellular Cy3-labeled a-syn, using the Zen-software, confirmed that the $\mathbf{c}$ area/cell and $\mathbf{d}$ intensity/cell were significantly decreased in the antibody-treated cultures. Scale bars $=10 \mu \mathrm{m}$. Data are presented as mean \pm SD from three independent experiments and levels of significance were set to ${ }^{*} P<0.05,{ }^{* *} P<0.01$, and ${ }^{* *} P<0.001$ 
$0.05 \mu \mathrm{M} \alpha$-syn oligomers pre-incubated with mAb47 for $1 \mathrm{~h}$ at $37^{\circ} \mathrm{C}$ was used as a positive $(0 \mathrm{~h})$ control.

\section{Analyses and statistics}

When applicable, the results are presented as mean \pm standard deviation. For statistical analyses, two-tailed Mann-Whitney $U$ test (GraphPad Prism) was used and the levels of significance were set to ${ }^{*} P<0.05,{ }^{* *} P<0.01$, and ${ }^{* * *} P<0.001$. The total number of observations was used for the statistical analyses. All of the experiments were performed on independent cell cultures, derived from mouse embryos of three different pregnant females. A wide-field microscope (Zeiss AxioImager Z1) was used for quantifications of $\alpha$-syn accumulation ( $\times 40$ magnification). The area and intensity of the Cy3- $\alpha$-syn fluorescence signal was analyzed using ZEN 2012 software. In

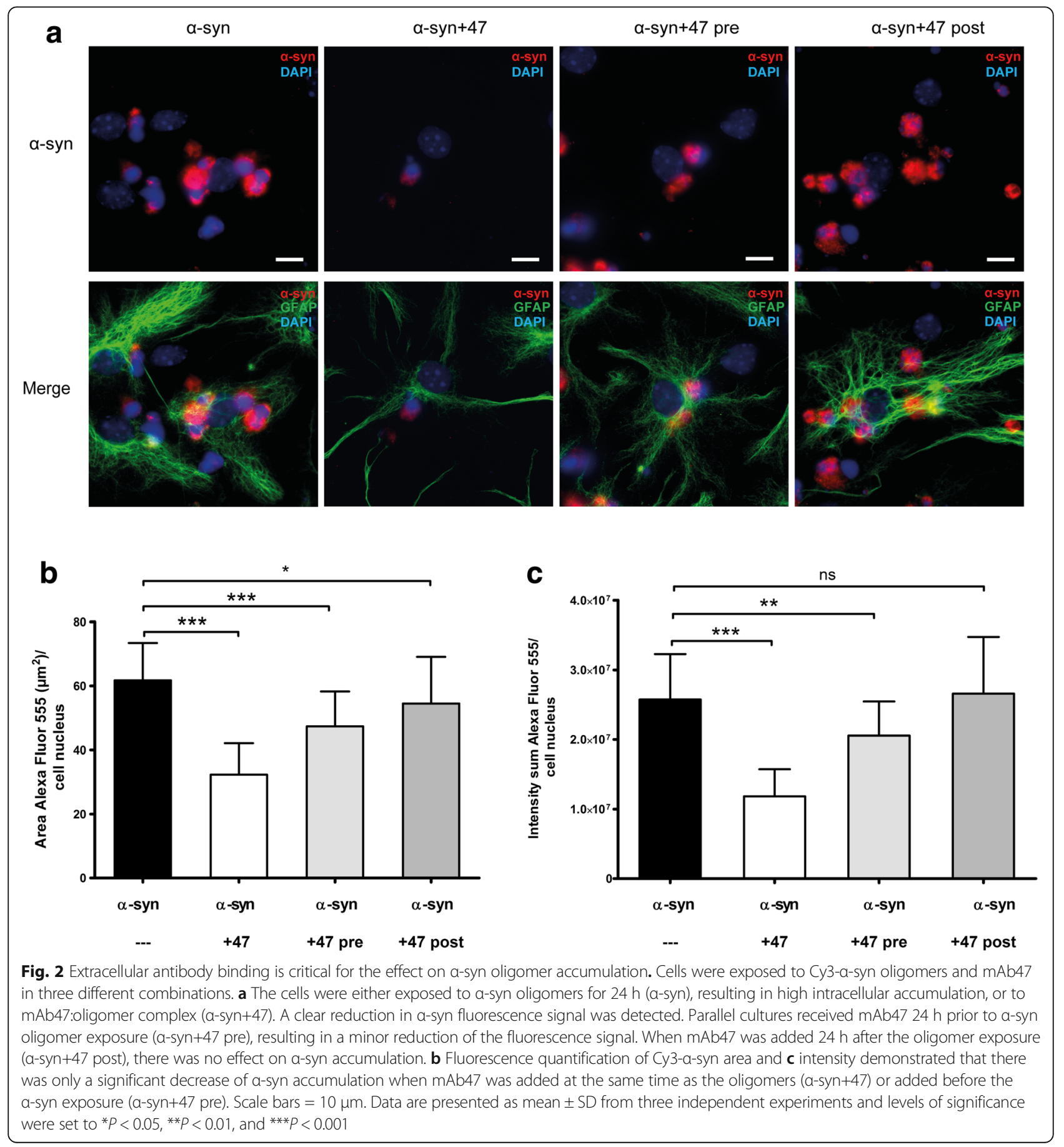


total, 45 images for each treatment (15 images per sample) were included in the statistical analysis. Values were normalized against the number of viable nuclei. Confocal micrographs were taken with a Zeiss LSM 700 confocal microscope ( $\times 63$ magnification).

Mitochondrial morphology in cell light mitochondriaGFP transfected cells was quantified manually. The number of cells with disrupted mitochondrial networks was counted and normalized against the total number of transfected, GFP-expressing cells. Cells with mitochondria displaying a low degree of branching, signs of swelling, and a dotted pattern were addressed as cells with a "disrupted mitochondrial network." In total, 45 images for each treatment (15 images per sample) were included in the analysis that was performed in a blinded fashion. At total of 250 cells or more were counted per sample.

\section{Results}

Oligomer-selective antibodies prevent accumulation of asyn in cultured astrocytes

In order to assess the extent of complex formation of antibodies and oligomers prior to cell exposure, an $\alpha$ syn oligomer-selective sandwich ELISA was used. In the presence of mAb47, there was a $96 \%$ decrease in the ELISA signal, demonstrating an almost complete mAb47:oligomer complex formation (hereafter referred to as Ab:oligomer complex) (Fig. 1a).

Co-cultures of astrocytes, neurons, and oligodendrocytes were exposed to Cy3-labeled $\alpha$-syn oligomers or to Ab:Cy3-oligomer complexes. In the initial analysis, we included three different oligomer-selective antibodies: mAb47 (IgG1) [9], mAb49G (IgG1) [32], and mAb38E2 (IgG2b) [26]. Immunocytochemistry against

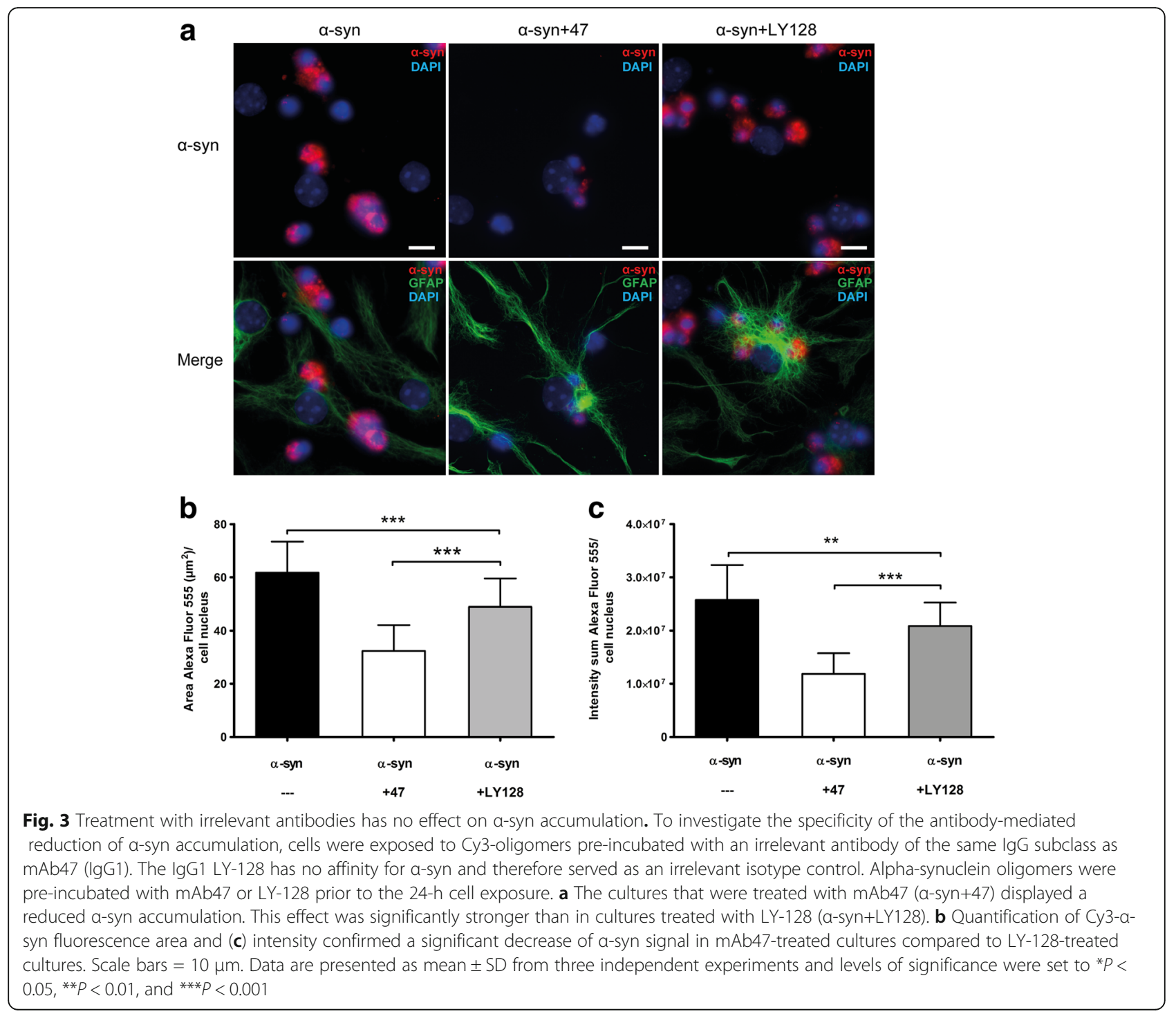


the astrocytic marker GFAP demonstrated that preincubation of oligomers with any of the three antibodies resulted in a reduced $\alpha$-syn accumulation in the astrocytes (Fig. 1b). Measurements of the intracellular Cy3-labeled $\alpha$-syn confirmed that the area and the intensity of the $\alpha$-syn deposits were significantly decreased in the Ab:oligomer complex-treated cultures, as compared to cultures that had been treated with oligomers alone $(p<0.0001)$ (Fig. 1c, d). Since $\mathrm{mAb} 47$ displayed the highest capability to reduce astrocytic $\alpha$-syn accumulation, we focused on this antibody for the subsequent experiments.

\section{Extracellular antibody-antigen binding is critical for re- duced a-syn accumulation}

To investigate if the oligomer-selective antibodies could affect the $\alpha$-syn accumulation in astrocytes when added to the cells before or after oligomer exposure, cells were exposed to $\mathrm{mAb} 47$ for $24 \mathrm{~h}$, either prior to or after $\alpha$ syn oligomer exposure. For both of these experiments, there were significantly less reduction of astrocytic $\alpha$-syn accumulation, as compared to the Ab:oligomer complex exposed cultures (Fig. 2a). Quantifications of the area
(Fig. 2b) and intensity (Fig. 2c) of the Cy3- $\alpha$-syn signal demonstrated that the $24 \mathrm{~h}$ pre-incubation of the cells with $\mathrm{mAb} 47$ resulted in a low, but significant reduction in $\alpha$-syn accumulation, as compared to exposure to $\alpha$ syn oligomers alone (area, 20.1\% reduction, $p<0.0001$; intensity, 23.2\% reduction, $p=0.0029$ ).

When the mAb47 antibody was added after the oligomer exposure, no reduction in Cy3- $\alpha$-syn intensity and only a minor reduction in Cy3- $\alpha$-syn-positive area (11.7\% reduction, $p=0.0292)$ could be detected. These results indicate that extracellular antibody-antigen interaction is crucial for an effective antibody-mediated reduction of the $\alpha$-syn deposits in the astrocytes. To assess the specificity of the observed antibody-mediated effect, we compared mAb47 to an irrelevant IgG1 antibody, LY-128, targeting flagellin in bacteria (Mabtech $A B$, Nacka Strand, Sweden) [33]. LY-128 was mixed with $\alpha$ syn oligomers for $1 \mathrm{~h}$ at $37{ }^{\circ} \mathrm{C}$ and added to the cells for $24 \mathrm{~h}$. Microscopy analyses indicated that the irrelevant IgG had some effect on $\alpha$-syn oligomer accumulation, but that the mAb47 antibody had a clearly stronger reducing effect (Fig. 3a). Quantification of the area (Fig. 3b) and the intensity (Fig. 3c) of the Cy3- $\alpha$-syn signal

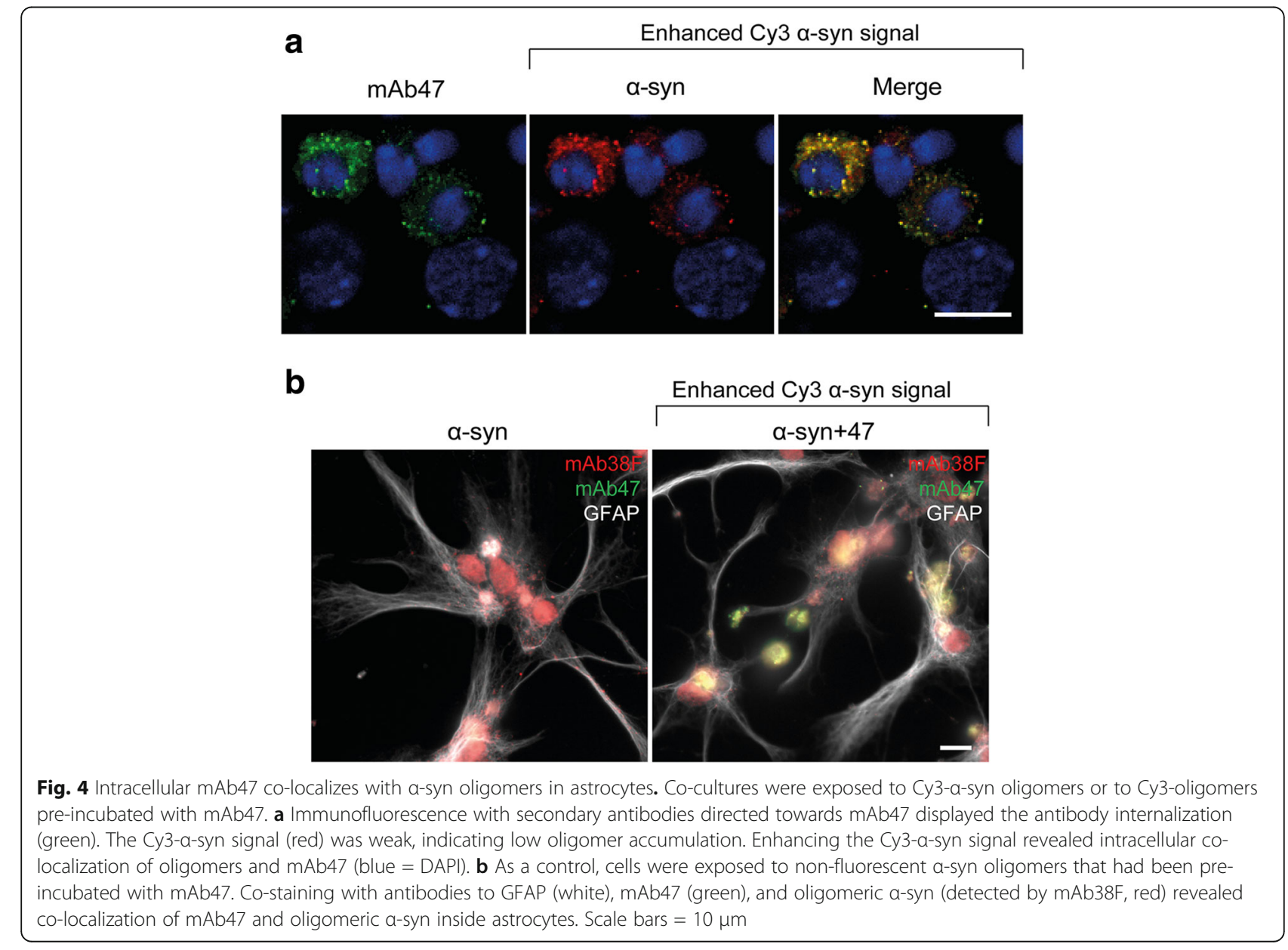


verified that there was a small but significant reduction of $\alpha$-syn accumulation in the presence of the LY-128 antibody. However, there was a pronounced reduction of $\alpha$-syn accumulation in the presence of mAb47 $(p<$ 0.0001, compared to the effect of LY-128). Our results indicate that the irrelevant antibody can affect the accumulation to some degree, possibly by activating the astrocytes to a more reactive state by binding to their Fcreceptors.

\section{Intracellular mAb47 co-localizes with a-syn in astrocytes} To study the intracellular location of ingested mAb47, the cell cultures were stained with a secondary antimouse IgG antibody. Analyses revealed that the ingested mAb47 had perinuclear localization (Fig. 4a). The Cy3- $\alpha$-syn signal was very weak, but intracellular co-localization of mAb47 and $\alpha$-syn could be detected when the exposure time of the Cy3-channel was increased (Fig. 4a). The oligomer-selective antibody mAb38F [26] consistently displayed a similar staining pattern and co-localized with the mAb47 signal (Fig. 4b). These results indicate that although most of the Ab:oligomer complexes were cleared, and a small fraction of the Ab:oligomer complexes was still intact and present inside the astrocytes.

\section{Intracellular a-syn oligomers co-localize with LAMP-1}

In line with previous results (Lindström et al. 2017), $\alpha$ syn oligomers were found to co-localize with the lysosomal/endosomal marker LAMP-1 after $24 \mathrm{~h}$ exposure (Fig. 5a). Also in the Ab:oligomer complex-treated cultures, the ingested $\alpha$-syn localized to LAMP-1 containing compartments at $24 \mathrm{~h}$ (Fig. $5 \mathrm{~b}$ ). However, due to the very low levels of intracellular $\alpha$-syn in these cultures (in relation to the cultures treated with only oligomers), the signal had to be enhanced to be visible.

\section{mAb47 rescues astrocytes from mitochondrial network disruption}

Labeling of the mitochondria with cell light mitochondria-GFP visualized a distinct mitochondrial swelling and increased mitochondrial fragmentation in astrocytes exposed to $0.05 \mu \mathrm{M} \alpha$-syn oligomers (Fig. 6a). In contrast, the mitochondrial networks in

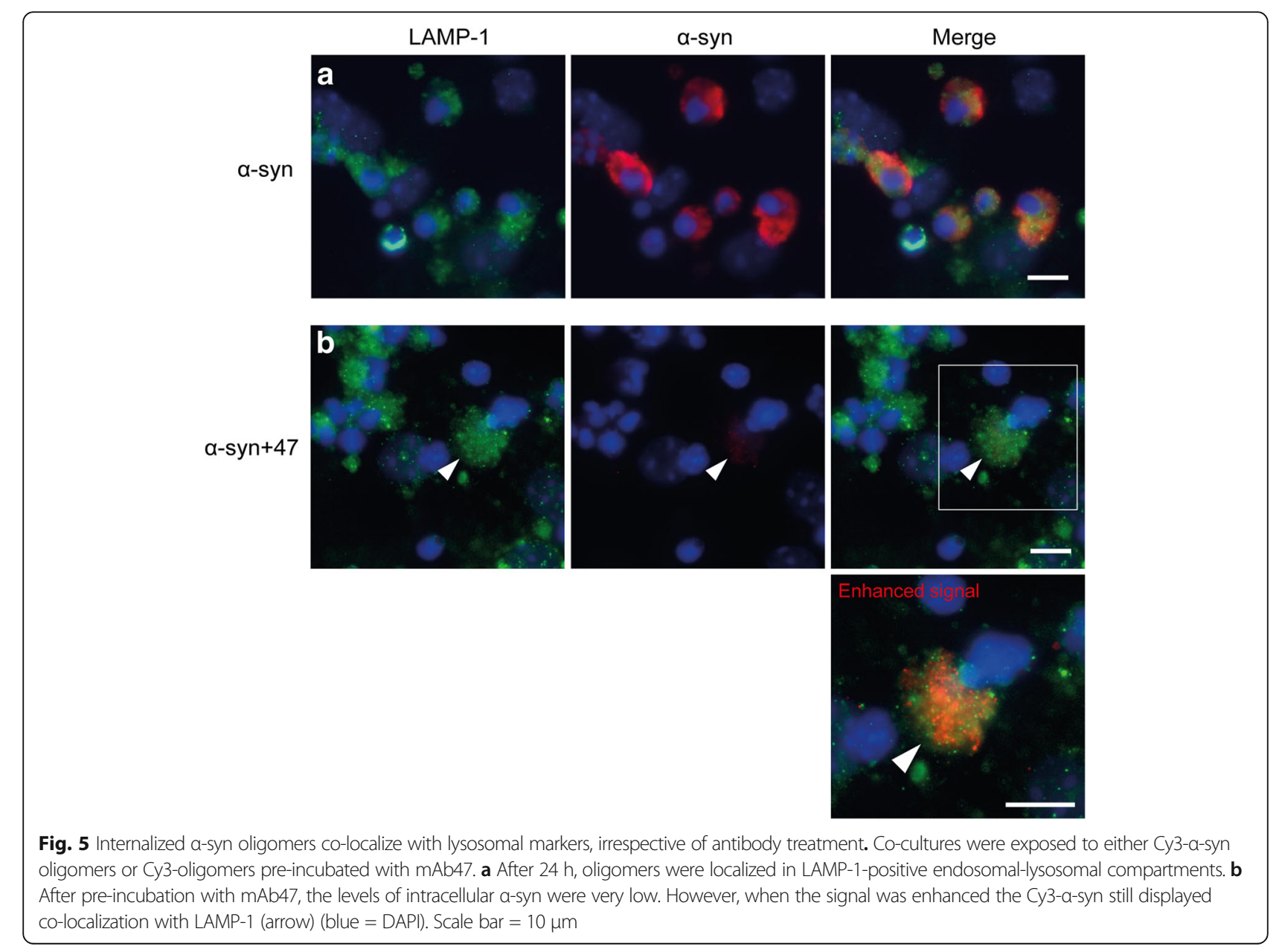



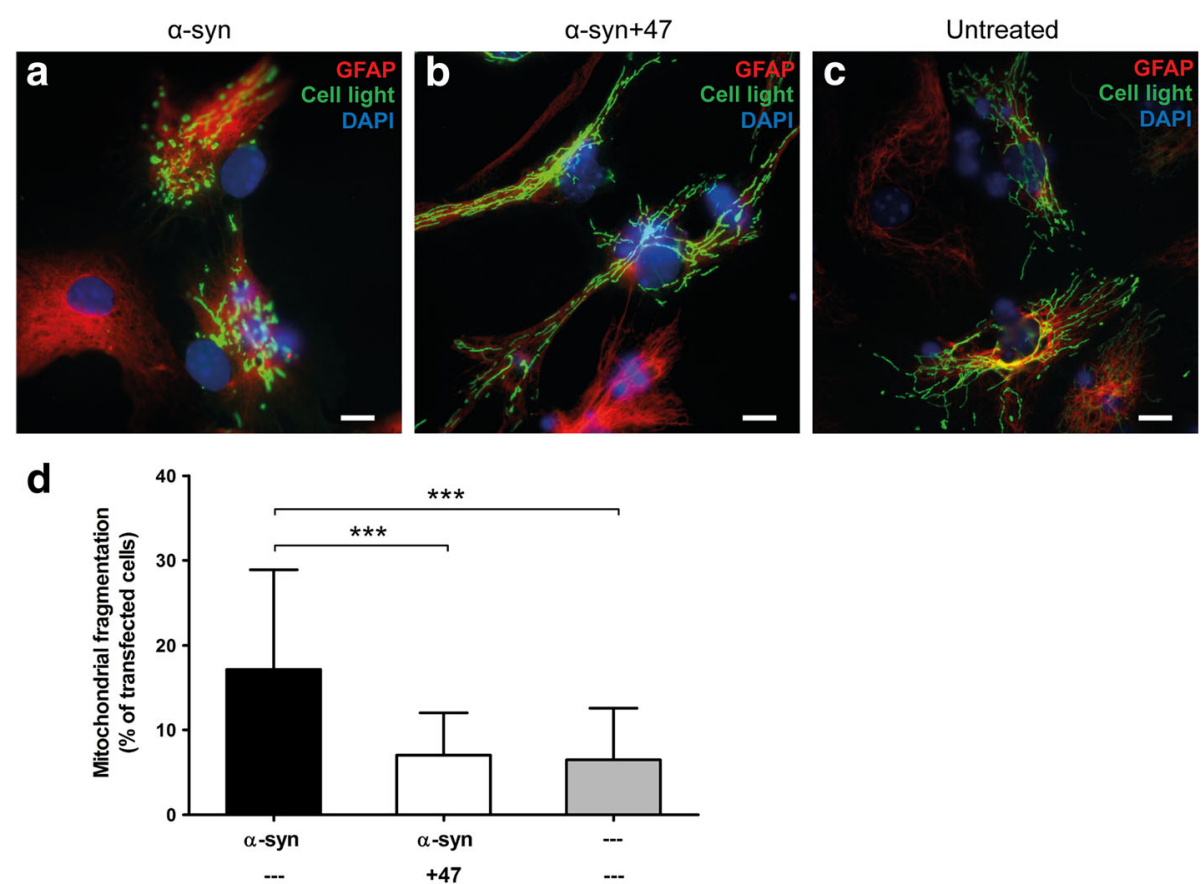

Fig. 6 Treatment with mAb47 prevents a-syn oligomer-mediated mitochondrial stress effects. During the $24 \mathrm{~h}$ exposure to a-syn oligomers or Ab:oligomer complexes, cells were transfected with Cell light Mitochondria-GFP to label the mitochondria. a Astrocytes exposed to a-syn oligomers frequently displayed a disrupted mitochondrial network and mitochondrial swelling. $\mathbf{b}$ The astrocytes in cultures exposed to a-syn oligomers pre-incubated with mAb47 displayed an elongated, branched mitochondrial network throughout the cells, similar to that of $\mathbf{c}$ non-treated cells. $\mathbf{d}$ Cells with disrupted mitochondrial networks were counted and normalized against the number of transfected cells. Oligomer exposure led to a clear increase in cells with mitochondrial fragmentation, whereas cultures exposed to oligomers pre-incubated with mAb47 did not significantly differ from the untreated control cells. Scale bars $=10 \mu \mathrm{m}$. Data are presented as mean \pm SD from three independent experiments and levels of significance were set to ${ }^{*} P<0.05,{ }^{* *} P<0.01$, and ${ }^{* *} P<0.001$

astrocytes exposed to the Ab:oligomer complex remained intact (Fig. 6b) as compared to untreated control cells (Fig. 6c). Quantification of fluorescence images revealed a significant increase of cells with fragmented mitochondria after exposure to $\alpha$-syn oligomers. In the presence of $\mathrm{mAb} 47$, the percentage of cells with fragmented mitochondria was similar to control cultures (Fig. 6d).

\section{Endosomal-lysosomal inhibitors do not alter the antibody-mediated effects}

In order to investigate the influence of the endosomal/lysosomal pathway on the antibody-mediated $\alpha$ syn reduction in astrocytes, we pre-incubated cells with the lysosomal inhibitors bafilomycin or chloroquine for $30 \mathrm{~min}$ prior to the Ab:oligomer complex exposure. The inhibitors were also present during the 24-h exposure. Neither of the inhibitors affected the mAb47-mediated reduction of $\alpha$-syn deposits (Fig. 7a). Measurement of the area (Fig. 7b) and the intensity (Fig. 7c) of the Cy3- $\alpha$-syn signal confirmed that the inhibitors did not interfere with the action of mAb47.
The presence of $\mathrm{mAb} 47$ reduces intracellular a-syn deposits and promotes clearance of extracellular a-syn Next, the effect of mAb47 on the total intra- and extracellular levels of $\alpha$-syn was investigated. For this purpose, time-lapse recordings of co-cultures were performed during the 24-h Cy3- $\alpha$-syn oligomer exposure. In line with our immunocytochemistry data, the Cy3- $\alpha$-syn oligomers accumulated inside the astrocytes over time (Fig. 8, upper panel). Already after $15 \mathrm{~min}$, the accumulation of internalized oligomers was evident. However, when cells were exposed to Ab:oligomer complexes, only a very low intracellular accumulation of Cy3- $\alpha$-syn was observed over time (Fig. 8, lower panel). Moreover, no increase in extracellular Cy3-positive aggregates could be detected in mAb47treated cultures. In line with that observation, a marked decrease in extracellular $\alpha$-syn in the presence of the oligomer-selective antibodies mAb47, mAb49G, or mAb38E2 was detected in media analysis using an $\alpha$-syn sandwich ELISA (Fig. 9a). The concentration of $\alpha$-syn in media from the mAb47treated samples had decreased most $(86 \%$ reduction, $p=0.0022)$, compared to conditioned media from 

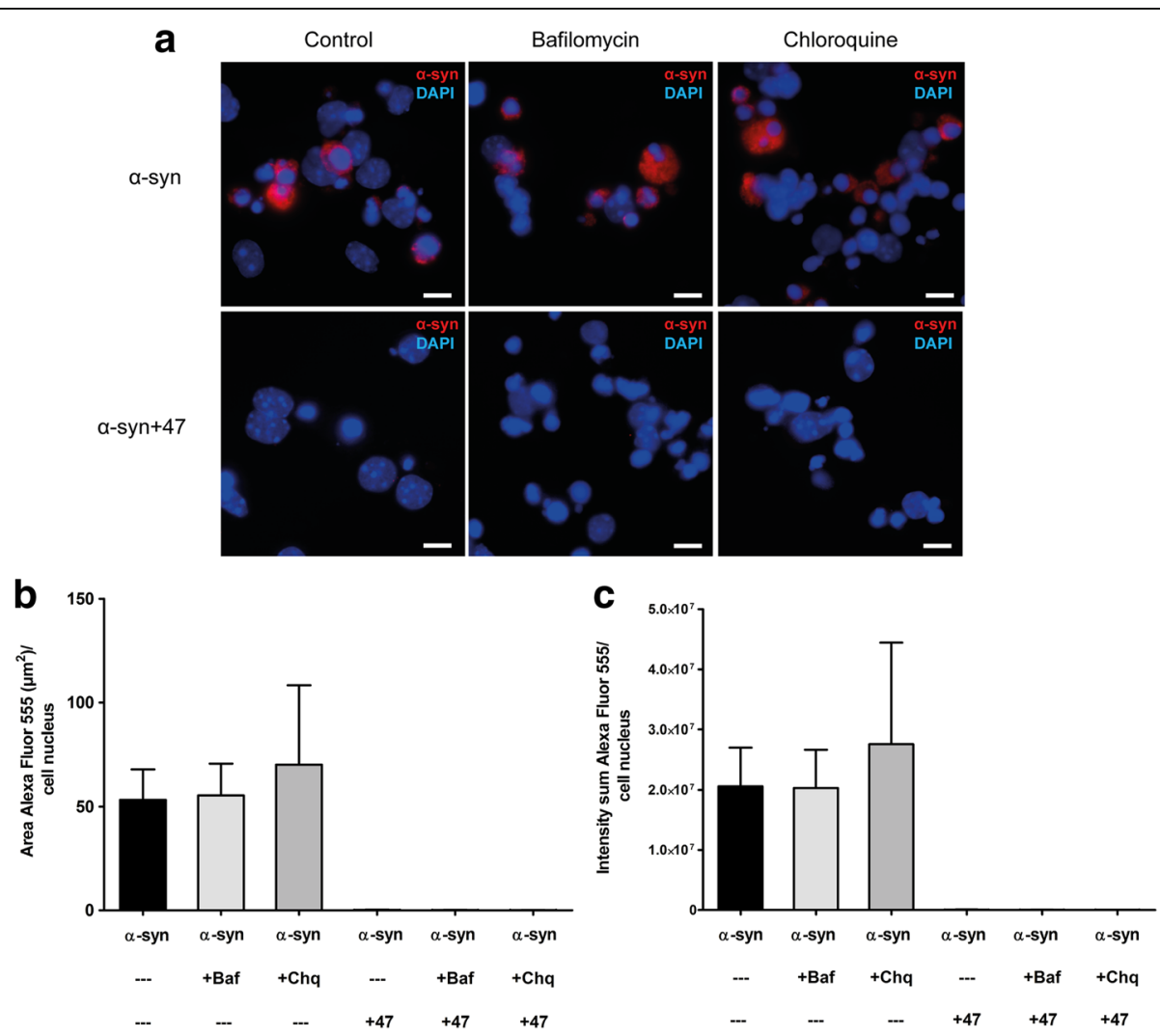

Fig. 7 Lysosomal-endosomal inhibition does not alter the antibody-mediated effect on oligomer accumulation. a Co-cultures were exposed to either Cy3-a-syn oligomers or to mAb47-treated oligomers for $24 \mathrm{~h}$, in combination with the lysosomal inhibitors bafilomycin (+Baf) or chloroquine (+Chq). The a-syn accumulation was unchanged, both in the absence and presence of mAb47. Hence, chemical inhibition of the lysosomal pathway did not alter the mAb47-mediated reduction of a-syn accumulation. b Fluorescence quantification of Cy3-a-syn area and (c) intensity confirmed that the inhibitors did not reduce the antibody-mediated effect on a-syn accumulation. Scale bars $=10 \mu \mathrm{m}$. Data are presented as mean \pm SD from three independent experiments and levels of significance were set to ${ }^{*} P<0.05$, ${ }^{*} P<0.01$, and ${ }^{* * *} P<0.001$

cells exposed to $\alpha$-syn oligomers only. However, also mAb49G (83\% reduction, $p=0.0022)$ and $\mathrm{mAb38E2}$ (76\% reduction, $p=0.0022$ ) were found to decrease extracellular $\alpha$-syn.

\section{Extracellular levels of complex-bound a-syn are reduced whereas mAb47 remains at high levels}

To further study the effect of oligomer-selective antibodies on extracellular $\alpha$-syn clearance, we performed immunoprecipitation on cell culture media. Protein Gcoupled beads were used to pull down the Ab:oligomer complexes present in the media. Western blotting of the immune precipitated samples using mAb211 displayed a reduction in extracellular, complex-bound $\alpha$-syn in the $24 \mathrm{~h}$ samples from three cell batches, as compared to the control (Fig. 9b). In the control media (harvested prior to any cell contact), a range of high molecular weight $\alpha$-syn species were detected as well as monomers $(14 \mathrm{kDa})$ and dimers $(35 \mathrm{kDa})$. In the $24 \mathrm{~h}$ samples, the high molecular weight signals had diminished and the monomers or dimers were no longer detectable. Quantification of the total $\alpha$-syn signal per lane (excluding IgG chain bands) revealed a 77\% decrease of the total $\alpha$-syn signal (Fig. 9c). Interestingly, at both time points, the heavy and light chain bands from mAb47 (at 50 and $25 \mathrm{kDa}$, respectively) were detected (Fig. 9b). When the signal intensities of the heavy and light IgG chain bands were measured, we found only a minor reduction $(26 \%)$ in the $24 \mathrm{~h}$ samples compared to the $0 \mathrm{~h}$ control (Fig. $9 \mathrm{~d}$ ).

\section{Discussion}

Immunotherapy has emerged as a promising method to target $\alpha$-syn pathology, but the underlying mechanisms and the role of different cell types are poorly understood. Whether astrocytes are involved in the cellular responses to $\alpha$-syn immunotherapy has not been previously addressed. Here, we demonstrate for the first time that oligomerselective antibodies can increase clearance of pathological $\alpha$-syn and maintain healthy mitochondria in astrocytes.

We have previously shown that treatment with the oligomer-selective antibody mAb47 leads to lowered $\alpha$ syn oligomer levels in the spinal cord of transgenic A30P $\alpha$-syn mice, correlating with ameliorated motor symptoms [9]. In the present study, we investigated the 


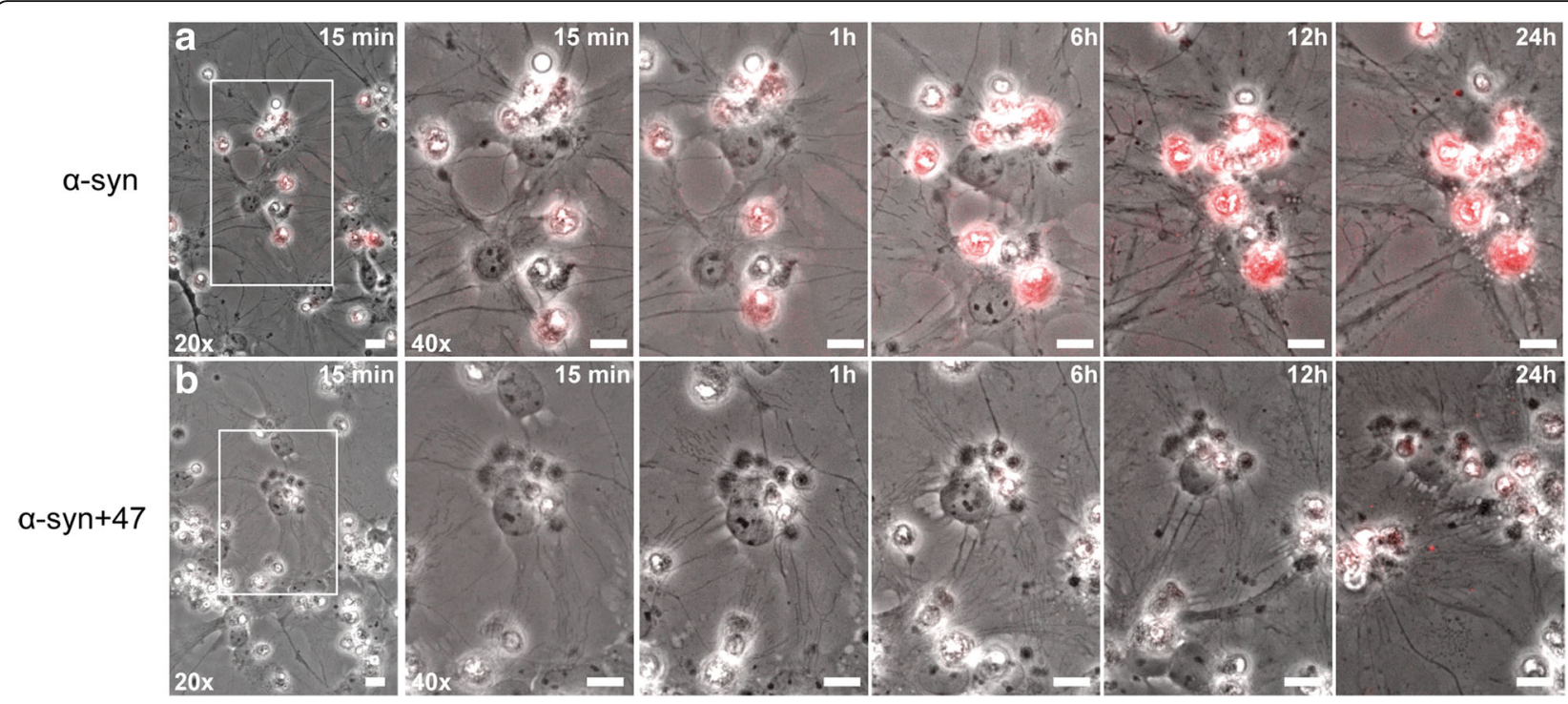

Fig. 8 The presence of mAb47 slows down astrocytic accumulation of a-syn oligomers. Co-cultures were exposed to either Cy3-a-syn oligomers or to mAb47-treated oligomers and monitored with time-lapse imaging for $24 \mathrm{~h}$. Areas highlighted with white rectangles to the left (20x) are displayed at higher magnification to the right (40x). When cells were exposed to oligomers alone, the astrocytic accumulation of fluorescent a-syn (red) was rapid, with deposits detectable already after 15 min that were increasing throughout the experiment (a). Exposure to mAb47-treated oligomers led to a much lower accumulation in astrocytes. At 24 h, a weak Cy3-a-syn signal was visible in the astrocytes (b). Moreover, no free-floating fluorescent aggregates were observed in the cell media, suggesting an overall increased clearance of a-syn oligomers (scale bars = $10 \mu m$ )

effects of three different oligomer-selective antibodies: mAb49G, mab38E2, and mAb47, on $\alpha$-syn-induced pathology in a co-culture system of astrocytes, neurons, and oligodendrocytes. The astrocytes were found to ingest large amounts of oligomeric $\alpha$-syn that accumulated as intracellular deposits and caused mitochondrial impairment, similar to previous observations [25]. Interestingly, the three oligomer-selective antibodies displayed different capacities in reducing the intracellular $\alpha$-syn deposits, with mAb47 being the most effective. The varying effects of the antibodies could be due to differences in their interaction with $\alpha$-syn oligomers in the extracellular milieu or to differences in the interaction of the antibodies to extracellular or intracellular receptors, depending on their different IgG sub-classes [34, 35]. Our pull-down Western blot analysis demonstrated that although the oligomers of the Ab:oligomer complexes were cleared from the culture, the antibodies remained. It could therefore be speculated that the astrocytes actively recycled and secreted the antibodies, whereas the oligomers in the complex were effectively degraded by the cells. Recycling of antibodies has been suggested to be crucial in immunotherapy, by enabling each antibody to bind to its antigen multiple times and thereby increase the clearance of the target protein [36].

In contrast to the $\alpha$-syn oligomer-selective mAb47, the irrelevant antibody of the same IgG isotype only had a modest effect on the $\alpha$-syn accumulation. This result indicates that the mechanism of action includes a direct interaction between $\alpha$-syn and $\alpha$-syn-oligomer-selective antibodies and is not only the result of a general glial activation (due to antibody binding to the astrocytes' Fcreceptors). Moreover, addition of the oligomer-selective antibodies before the $\alpha$-syn oligomer exposure had only a minor effect on the intracellular deposition whereas addition of the antibodies after the oligomer exposure had no effect at all. Taken together, these experiments demonstrated that immune complex formation needs to occur in the extracellular space prior to internalization in order to reduce intracellular $\alpha$-syn accumulation.

Although the mechanisms responsible for the effectiveness of passive immunization against $\alpha$-syn pathology are incompletely understood, its beneficial effects have been suggested to include increased clearance of toxic $\alpha$-syn species from the extracellular space [10], steric hindrance of $\alpha$-syn aggregation [32], and reduced $\alpha$-syn propagation between cells $[37,38]$. These previous investigations have focused on processes in neurons [38], neuron-like cell lines, or microglia [10], but have not involved astrocytes. Being the most abundant glial cell type in the central nervous system, astrocytes play an important role in maintaining brain homeostasis [20]. In addition, astrocytes respond to neurodegenerative disorders, including PD, through astrogliosis, a process in which they convert to a reactive inflammatory state [23, 39]. The complex role of astrocytes in the pathological brain is largely dependent upon their release and uptake of substances from the micro-environment that they 


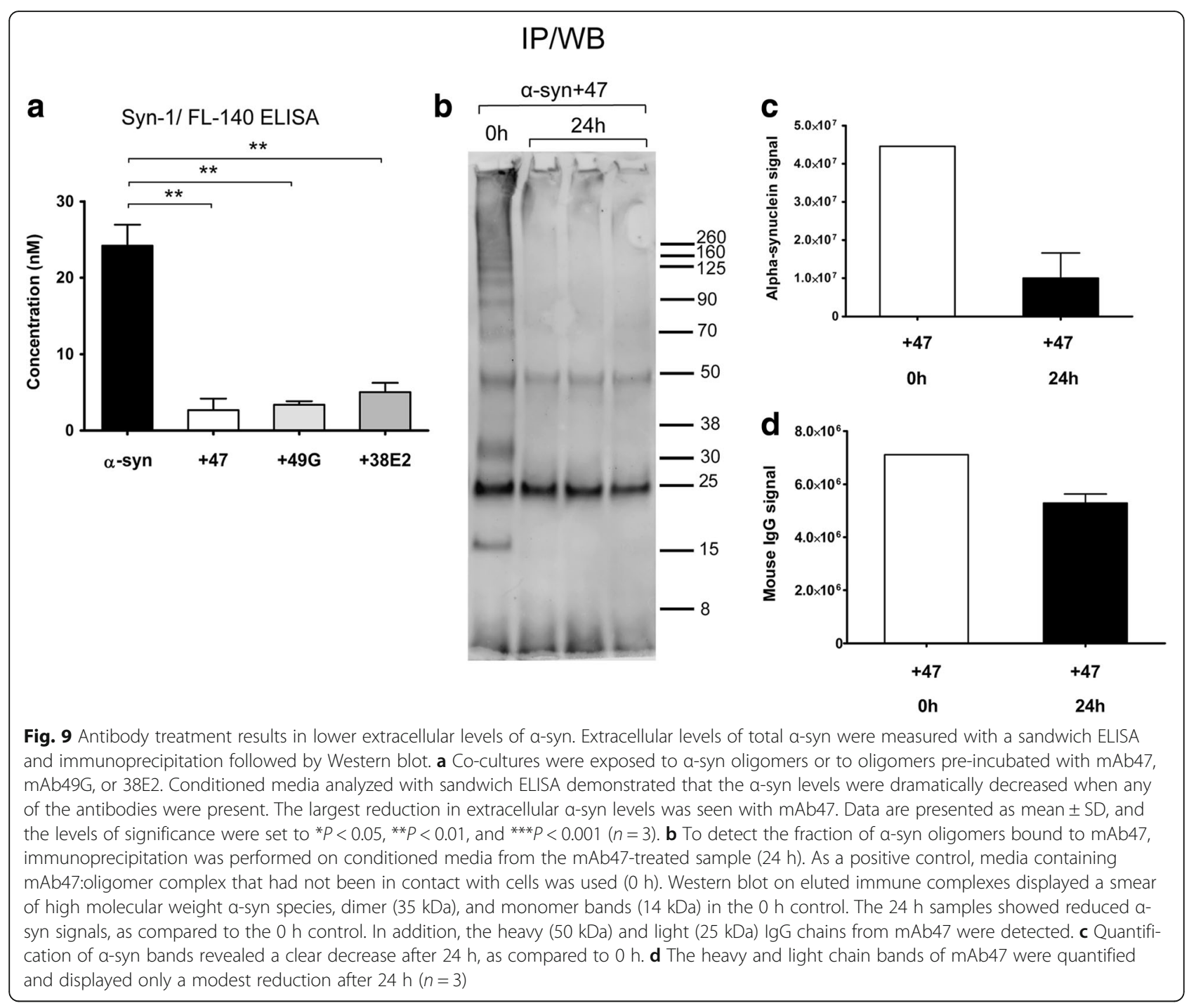

share with the neurons [20]. Reactive astrocytes effectively engulf dead cells, synapses, and protein aggregates of amyloid beta (A $\beta)$ and $\alpha$-syn $[27,40-46]$, and we and others have shown that astrocytes may play an important role in spreading of pathogenic proteins [47].

Studies on transgenic mice and cell models have further indicated that anti- $\alpha$-syn antibody treatment can mediate an upregulation of autophagy [13] and promote lysosomal degradation [10, 48]. In our immunocytochemical analyses, we detected low levels of intracellular $\alpha$-syn after Ab:oligomer complex exposure. However, by enhancing the fluorescence signal, we could demonstrate that there were still low levels of Ab:oligomer complexes present within Lamp-1-positive structures in the astrocytes, indicating that at least some of the ingested complexes were directed to the endosomal-lysosomal pathway. However, since inhibition of the lysosomal pathway did not have an impact on the reduced accumulation, we speculate that the majority of the
Ab:oligomer complexes may be degraded by another route, such as the proteasome pathway or another not yet described mechanism, but additional investigations will be needed to sort that out. Irrespective of degradation pathway, our data indicate that the astrocytic clearance of already ingested Ab:oligomer complexes is rapid. Another possible explanation for the reduced intracellular deposits of $\alpha$-syn could be a lower uptake or an increased recycling and secretion of the engulfed Ab:oligomer complexes. However, our ELISA and Western blot data of conditioned media showed that both the intra- and extracellular levels of $\alpha$-syn were lowered in the antibody-treated cultures. In accordance, the timelapse recordings indicated a treatment-related decrease in the astrocytic accumulation and absence of freefloating Ab:oligomer complexes. Altogether, our data demonstrate that the Ab:oligomer complexes do not accumulate in the astrocytes to the same extent as $\alpha$-syn oligomers alone, but are rather cleared from the culture. 
There have been several reports about how $\alpha$-syn aggregates induce mitochondrial dysfunction in neurons, including disturbance of the mitochondria fission-fusion homeostasis, autophagosome synthesis, and mitophagy function [49-51]. Our previous results demonstrated a widespread mitochondrial fragmentation and dysfunction in $\alpha$-syn oligomer treated astrocytes, indicating that the accumulation of $\alpha$-syn disrupts the autophagosomal and mitophagy machinery [25].

\section{Conclusions}

The present study demonstrates that $\alpha$-syn oligomerselective antibodies effectively prevent accumulation of toxic $\alpha$-syn oligomers in the astrocytes and thereby rescue them from mitochondrial impairment. Neurodegenerative diseases, including PD, are defined by loss of brain homeostasis [22, 52-55], which at least partly could be due to the severely stressed astrocytes that are unable to fulfill their normal tasks [20-22]. Hence, maintaining astrocytic functionality is probably a crucial component for immunotherapy to be successful. In addition, increased astrocytic clearance of soluble $\alpha$-syn oligomers may reduce PD progression, by preventing further spreading of the $\alpha$-syn pathology. In order to optimize the design of future antibody-based therapies, we believe that more studies are needed, focusing on various cell types, including astrocytes.

\section{Abbreviations \\ Baf: Bafilomycin; Chq: Chloroquine; CNS: Central nervous system; Cy3: Cyanine dye 3; DAPI: 4',6-Diamidino-2-phenylindole; GFAP: Glial fibrillary acidic protein; GFP: Green fluorescent protein; HNE: 4-Hydroxy-2-nonenal; HPLC: High-performance liquid chromatography; IgG: Immunoglobulin G; IP: Immunoprecipitation; LAMP-1: Lysosome-associated membrane protein-1; LB: Lewy body; mAb: Monoclonal antibody; NGS: Normal goat serum; PBS: Phosphate-buffered saline; PD: Parkinson's disease; \\ PFA: Paraformaldehyde; PVDF: Polyvinylidene difluoride; SEC: Size exclusion chromatography; TBS: Tris-buffered saline; a-syn: a-Synuclein}

\section{Acknowledgements}

This study was supported by grants from the Swedish Research Council, the Swedish Parkinson Foundation, the Swedish Alzheimer Foundation, Åhlén Foundation, The Swedish Dementia Association Foundation, Hedlund's Foundation, Lennart and Christina Kalén, William N. \& Bernice E. Bumpus Foundation Innovation Award, Marianne and Marcus Wallenberg Foundation, the Swedish Brain Foundation, Parkinson Research Foundation, King Gustaf $V$ and Queen Victoria's Foundation of Freemasons, the U4 Ageing Brain Network, and the Uppsala Berzelii Center for Neurodiagnostics.

\section{Availability of data and materials}

All data generated or analyzed during this study are included in this article.

\section{Authors' contributions}

GG designed and performed the experiments, interpreted the data, and wrote the manuscript; VL performed the experiments, participated in interpreting the data, and revised the manuscript. JR performed the experiments, participated in interpreting the data, and revised the manuscript. EN participated in the design of the study and revised the manuscript. LL participated in the design of the study and revised the manuscript. JB participated in the design of the study, interpreted the data, and revised the manuscript. Ml participated in the design of the study, interpreted the data, and revised the manuscript. AE designed the study, interpreted the data, coordinated the study, and wrote the manuscript. All authors have read and approved the final manuscript.

\section{Ethics approval}

All experiments involving animals were performed at Uppsala University, Sweden. The experiments were approved by the Uppsala County Animal Ethics Board (ethical permit number: C75/13, valid 2013-06-28 to 2018-06-28), following the rules and regulations of the Swedish Animal Welfare Agency, in compliance with the European Communities Council Directive of 22 September 2010 (2010/63/EU).

\section{Consent for publication}

Not applicable.

\section{Competing interests}

EN is employed by BioArctic Neuroscience AB. LL is co-founder of BioArctic $A B$ and stock owner. This does not alter to the Journal of Neuroinflammation policies on sharing data and materials. None of the authors have any financial relationship with the organizations that sponsored the research. The other authors declare that they have no competing interests.

\section{Publisher's Note}

Springer Nature remains neutral with regard to jurisdictional claims in published maps and institutional affiliations.

\section{Author details}

${ }^{1}$ Molecular Geriatrics, Department of Public Health and Caring Sciences, Rudbeck Laboratory, Uppsala University, SE-751 85 Uppsala, Sweden. ${ }^{2}$ BioArctic AB, Warfvinges väg 35, 11251 Stockholm, Sweden.

Received: 15 August 2017 Accepted: 1 December 2017

Published online: 11 December 2017

\section{References}

1. Spillantini MG, Crowther RA, Jakes R, Hasegawa M, Goedert M. Alphasynuclein in filamentous inclusions of Lewy bodies from Parkinson's disease and dementia with lewy bodies. Proc Natl Acad Sci U S A. 1998;95:6469-73.

2. Spillantini MG, Schmidt ML, Lee VM, Trojanowski JQ, Jakes R, Goedert M. Alpha-synuclein in Lewy bodies. Nature. 1997:388:839-40.

3. El-Agnaf OM, Salem SA, Paleologou KE, Curran MD, Gibson MJ, Court JA, Schlossmacher MG, Allsop D. Detection of oligomeric forms of alphasynuclein protein in human plasma as a potential biomarker for Parkinson's disease. FASEB J. 2006;20:419-25.

4. Ingelsson M. Alpha-synuclein oligomers-neurotoxic molecules in Parkinson's disease and other Lewy body disorders. Front Neurosci. 2016;10:408.

5. Danzer KM, Haasen D, Karow AR, Moussaud S, Habeck M, Giese A, Kretzschmar $\mathrm{H}$, Hengerer B, Kostka M. Different species of alpha-synuclein oligomers induce calcium influx and seeding. J Neurosci. 2007;27:9220-32.

6. Winner B, Jappelli R, Maji SK, Desplats PA, Boyer L, Aigner S, Hetzer C, Loher T, Vilar M, Campioni $\mathrm{S}$, et al. In vivo demonstration that alpha-synuclein oligomers are toxic. Proc Natl Acad Sci U S A. 2011;108:4194-9.

7. Chinta SJ, Mallajosyula JK, Rane A, Andersen JK. Mitochondrial alpha-synuclein accumulation impairs complex I function in dopaminergic neurons and results in increased mitophagy in vivo. Neurosci Lett. 2010;486:235-9.

8. Luth ES, Stavrovskaya IG, Bartels T, Kristal BS, Selkoe DJ. Soluble, prefibrillar alpha-synuclein oligomers promote complex I-dependent, Ca2+-induced mitochondrial dysfunction. J Biol Chem. 2014;289:21490-507.

9. Lindström V, Fagerqvist T, Nordstrom E, Eriksson F, Lord A, Tucker S, Andersson J, Johannesson M, Schell H, Kahle PJ, et al. Immunotherapy targeting alpha-synuclein protofibrils reduced pathology in (Thy-1)-h[A30P] alpha-synuclein mice. Neurobiol Dis. 2014:69:134-43.

10. Bae EJ, Lee HJ, Rockenstein E, Ho DH, Park EB, Yang NY, Desplats P, Masliah E, Lee SJ. Antibody-aided clearance of extracellular alpha-synuclein prevents cell-to-cell aggregate transmission. J Neurosci. 2012;32:13454-69.

11. Mandler M, Valera E, Rockenstein E, Weninger $H$, Patrick C, Adame A, Santic R, Meindl S, Vigl B, Smrzka O, et al. Next-generation active immunization approach for synucleinopathies: implications for Parkinson's disease clinical trials. Acta Neuropathol. 2014;127:861-79. 
12. Masliah E, Rockenstein E, Adame A, Alford M, Crews L, Hashimoto M, Seubert P, Lee M, Goldstein J, Chilcote T, et al. Effects of alpha-synuclein immunization in a mouse model of Parkinson's disease. Neuron. 2005;46:857-68.

13. Masliah E, Rockenstein E, Mante M, Crews L, Spencer B, Adame A, Patrick C, Trejo M, Ubhi K, Rohn T, et al. Passive immunization reduces behavioral and neuropathological deficits in an alpha-synuclein transgenic model of Lewy body disease. PLoS One. 2011;6:e19338.

14. Braak H, Sastre M, Del Tredici K. Development of alpha-synuclein immunoreactive astrocytes in the forebrain parallels stages of intraneuronal pathology in sporadic Parkinson's disease. Acta Neuropathol. 2007;114:231-41.

15. Wakabayashi K, Hayashi S, Yoshimoto M, Kudo H, Takahashi H. NACP/alphasynuclein-positive filamentous inclusions in astrocytes and oligodendrocytes of Parkinson's disease brains. Acta Neuropathol. 2000;99:14-20.

16. Terada S, Ishizu H, Yokota O, Tsuchiya K, Nakashima H, Ishihara T, Fujita D, Ueda K, Ikeda K, Kuroda S. Glial involvement in diffuse Lewy body disease. Acta Neuropathol. 2003;105:163-9.

17. Croisier E, Graeber MB. Glial degeneration and reactive gliosis in alphasynucleinopathies: the emerging concept of primary gliodegeneration. Acta Neuropathol. 2006;112:517-30.

18. PH T, Galvin JE, Baba M, Giasson B, Tomita T, Leight S, Nakajo S, Iwatsubo T, Trojanowski JQ, Lee VM. Glial cytoplasmic inclusions in white matter oligodendrocytes of multiple system atrophy brains contain insoluble alphasynuclein. Ann Neurol. 1998;44:415-22.

19. Iseki E, Marui W, Akiyama H, Ueda K, Kosaka K. Degeneration process of Lewy bodies in the brains of patients with dementia with Lewy bodies using alpha-synuclein-immunohistochemistry. Neurosci Lett. 2000;286:69-73.

20. Sofroniew MV, Vinters HV. Astrocytes: biology and pathology. Acta Neuropathol. 2010;119:7-35.

21. Eroglu C, Barres BA. Regulation of synaptic connectivity by glia. Nature. 2010;468:223-31.

22. Verkhratsky A, Nedergaard M, Hertz L. Why are astrocytes important? Neurochem Res. 2015:40:389-401.

23. Pekny $M$, Wilhelmsson $U$, Pekna $M$. The dual role of astrocyte activation and reactive gliosis. Neurosci Lett. 2014;565:30-8.

24. Piovesan E, Castilhos C, Pozza R, Michelon TF, Seelig DC, Santos AF, Bittar E, Keitel E, Goldani JC, Garcia CD, et al. Hemolytic-uremic syndrome after kidney transplantation. Transplant Proc. 2002;34:2779-80.

25. Lindström V, Gustafsson G, Sanders LH, Howlett EH, Sigvardson J, Kasrayan A, Ingelsson M, Bergström J, Erlandsson A. Extensive uptake of alphasynuclein oligomers in astrocytes results in sustained intracellular deposits and mitochondrial damage. Mol Cell Neurosci. 2017;

26. Fagerqvist $T$, Lindström V, Nordstrom E, Lord A, Tucker SM, Su X, Sahlin C, Kasrayan A, Andersson J, Welander $\mathrm{H}$, et al. Monoclonal antibodies selective for alpha-synuclein oligomers/protofibrils recognize brain pathology in Lewy body disorders and transgenic mice expressing the disease-causing A30P mutation. J Neurochem. 2013;

27. Söllvander S, Nikitidou E, Brolin R, Soderberg L, Sehlin D, Lannfelt L, Erlandsson A. Accumulation of amyloid-beta by astrocytes result in enlarged endosomes and microvesicle-induced apoptosis of neurons. Mol Neurodegener. 2016;11:38

28. Davis AA, Temple S. A self-renewing multipotential stem cell in embryonic rat cerebral cortex. Nature. 1994;372:263-6.

29. Johe KK, Hazel TG, Muller T, Dugich-Djordjevic MM, McKay RD. Single factors direct the differentiation of stem cells from the fetal and adult central nervous system. Genes Dev. 1996;10:3129-40.

30. Ravin R, Hoeppner DJ, Munno DM, Carmel L, Sullivan J, Levitt DL, Miller JL, Athaide C, Panchision DM, McKay RD. Potency and fate specification in CNS stem cell populations in vitro. Cell Stem Cell. 2008;3:670-80

31. Nasstrom T, Fagerqvist T, Barbu M, Karlsson M, Nikolajeff F, Kasrayan A Ekberg M, Lannfelt L, Ingelsson M, Bergstrom J. The lipid peroxidation products 4-oxo-2-nonenal and 4-hydroxy-2-nonenal promote the formation of alpha-synuclein oligomers with distinct biochemical, morphological, and functional properties. Free Radic Biol Med. 2011;50:428-37.

32. Näsström T, Goncalves S, Sahlin C, Nordstrom E, Screpanti Sundquist V, Lannfelt L, Bergstrom J, Outeiro TF, Ingelsson M. Antibodies against alpha-synuclein reduce oligomerization in living cells. PLoS One. 2011;6: e27230.

33. Magnusson K, Sehlin D, Syvanen S, Svedberg MM, Philipson O, Soderberg L, Tegerstedt K, Holmquist M, Gellerfors P, Tolmachev V, et al. Specific uptake of an amyloid-beta protofibril-binding antibody-tracer in AbetaPP transgenic mouse brain. J Alzheimers Dis. 2013;37:29-40.
34. Lux A, Yu X, Scanlan CN, Nimmerjahn F. Impact of immune complex size and glycosylation on lgG binding to human FcgammaRs. J Immunol. 2013; 190:4315-23.

35. Nimmerjahn F, Bruhns P, Horiuchi K, Ravetch JV. FcgammaRIV: a novel FCR with distinct lgG subclass specificity. Immunity. 2005;23:41-51.

36. Kasturirangan S, Rainey GJ, Xu L, Wang X, Portnoff A, Chen T, Fazenbaker C, Zhong $\mathrm{H}$, Bee J, Zeng Z, et al. Targeted Fcgamma receptor (FcgammaR)-mediated clearance by a biparatopic bispecific antibody. J Biol Chem. 2017;292:4361-70.

37. Games D, Valera E, Spencer B, Rockenstein E, Mante M, Adame A, Patrick C, Ubhi K, Nuber S, Sacayon P, et al. Reducing C-terminal-truncated alphasynuclein by immunotherapy attenuates neurodegeneration and propagation in Parkinson's disease-like models. J Neurosci. 2014;34:9441-54.

38. Tran HT, Chung CH, Iba M, Zhang B, Trojanowski JQ, Luk KC, Lee VM. Alphasynuclein immunotherapy blocks uptake and templated propagation of misfolded alpha-synuclein and neurodegeneration. Cell Rep. 2014;7:2054-65.

39. Neumann M, Kahle PJ, Giasson Bl, Ozmen L, Borroni E, Spooren W, Muller V, Odoy S, Fujiwara H, Hasegawa M, et al. Misfolded proteinase K-resistant hyperphosphorylated alpha-synuclein in aged transgenic mice with locomotor deterioration and in human alpha-synucleinopathies. J Clin Invest. 2002;110:1429-39.

40. Loov C, Hillered L, Ebendal T, Erlandsson A. Engulfing astrocytes protect neurons from contact-induced apoptosis following injury. PLoS One. 2012;7:e33090.

41. Jones RS, Minogue AM, Connor TJ, Lynch MA. Amyloid-beta-induced astrocytic phagocytosis is mediated by CD36, CD47 and RAGE. J Neurolmmune Pharmacol. 2013;8:301-11.

42. Chung WS, Clarke LE, Wang GX, Stafford BK, Sher A, Chakraborty C, Joung J, Foo LC, Thompson A, Chen C, et al. Astrocytes mediate synapse elimination through MEGF10 and MERTK pathways. Nature. 2013;504:394-400.

43. Chang GH, Barbaro NM, Pieper RO. Phosphatidylserine-dependent phagocytosis of apoptotic glioma cells by normal human microglia, astrocytes, and glioma cells. Neuro-Oncology. 2000;2:174-83.

44. Magnus T, Chan A, Linker RA, Toyka KV, Gold R. Astrocytes are less efficient in the removal of apoptotic lymphocytes than microglia cells: implications for the role of glial cells in the inflamed central nervous system. J Neuropathol Exp Neurol. 2002;61:760-6.

45. Sokolowski JD, Nobles SL, Heffron DS, Park D, Ravichandran KS, Mandell JW. Brain-specific angiogenesis inhibitor-1 expression in astrocytes and neurons: implications for its dual function as an apoptotic engulfment receptor. Brain Behav Immun. 2011;25:915-21.

46. Fellner L, Irschick R, Schanda K, Reindl M, Klimaschewski L, Poewe W, Wenning GK, Stefanova N. Toll-like receptor 4 is required for alpha-synuclein dependent activation of microglia and astroglia. Glia. 2013;61:349-60.

47. Victoria GS, Arkhipenko A, Zhu S, Syan S, Zurzolo C. Astrocyte-to-neuron intercellular prion transfer is mediated by cell-cell contact. Sci Rep. 2016;6:20762.

48. Spencer B, Emadi S, Desplats P, Eleuteri S, Michael S, Kosberg K, Shen J, Rockenstein E, Patrick C, Adame A, et al. ESCRT-mediated uptake and degradation of brain-targeted alpha-synuclein single chain antibody attenuates neuronal degeneration in vivo. Mol Ther. 2014;22:1753-67.

49. Ryan BJ, Hoek S, Fon EA, Wade-Martins R. Mitochondrial dysfunction and mitophagy in Parkinson's: from familial to sporadic disease. Trends Biochem Sci. 2015;40:200-10

50. Nakamura K. Alpha-synuclein and mitochondria: partners in crime? Neurotherapeutics. 2013;10:391-9.

51. Guardia-Laguarta C, Area-Gomez E, Rub C, Liu Y, Magrane J, Becker D, Voos W, Schon EA, Przedborski S. Alpha-synuclein is localized to mitochondriaassociated ER membranes. J Neurosci. 2014;34:249-59.

52. Coulter DA, Eid T. Astrocytic regulation of glutamate homeostasis in epilepsy. Glia. 2012;60:1215-26.

53. Giaume C, Kirchhoff F, Matute C, Reichenbach A, Verkhratsky A. Glia: the fulcrum of brain diseases. Cell Death Differ. 2007;14:1324-35.

54. Faroni A, Rothwell SW, Grolla AA, Terenghi G, Magnaghi V, Verkhratsky A. Differentiation of adipose-derived stem cells into Schwann cell phenotype induces expression of P2X receptors that control cell death. Cell Death Dis. 2013:4:e743.

55. Verkhratsky A, Sofroniew MV, Messing A, deLanerolle NC, Rempe D, Rodriguez JJ, Nedergaard M. Neurological diseases as primary gliopathies: a reassessment of neurocentrism. ASN Neuro. 2012;4. 